\title{
Correction to: Assessment of shunted piezoelectric devices for simultaneous noise and vibration reduction: comparison of passive, active and hybrid networks
}

\author{
Seyyed M. Hasheminejad • Mehran Shahraeeni $\mathbb{D}$
}

Published online: 16 January 2020

(C) Springer Nature B.V. 2020

Correction to: Meccanica (2018) 53:3209-3231

https://doi.org/10.1007/s11012-018-0885-4

that should be regarded as the final version by the reader.

Due to an unfortunate turn of events, this article was published without mention of the first author. Please find on this page all authors listed in the correct order

Publisher's Note Springer Nature remains neutral with regard to jurisdictional claims in published maps and institutional affiliations.

The original article can be found online at https:// doi.org/10.1007/s11012-018-0885-4.

S. M. Hasheminejad

Acoustics Research Laboratory, Center of Excellence in Experimental Solid Mechanics and Dynamics, School of Mechanical Engineering, Iran University of Science and Technology, Narmak, Tehran 16846-13114, Iran e-mail: hashemi@iust.ac.ir

M. Shahraeeni $(\bowtie)$

School of Mechanical Engineering, Iran University of Science and Technology, Narmak, Tehran 16846-13114, Iran

e-mail: shahraeeni@alumni.iust.ac.ir;

me.shahraeeni@yahoo.com 